\title{
Age Differences in Coupling of Intraindividual Variability in Mnemonic Strategies and Practice-Related Associative Recall Improvements
}

\author{
Christopher Hertzog \\ Georgia Institute of Technology
}

Ulman Lindenberger

Max Planck Institute for Human Development, Berlin, Germany

\author{
Martin Lövdén \\ Max Planck Institute for Human Development, Berlin, Germany; \\ Karolinska Institutet; and Stockholm University \\ Florian Schmiedek \\ Max Planck Institute for Human Development, Berlin, Germany, \\ and German Institute for International Educational Research \\ (DIPF) Frankfurt am Main, Frankfurt-am-Main, Germany
}

\begin{abstract}
The importance of encoding strategies for associative recall is well established, but there have been no studies of aging and intraindividual variability (IAV) in strategy use during extended practice. We observed strategy use and cued-recall test performance over 101 days of practice in 101 younger adults ( $M=25.6$ years) and 103 older adults $(M=71.3$ years) sandwiched by a pretest and posttest battery including an associative recall test. Each practice session included 2 lists of 12 number-noun pairedassociate (PA) items (e.g., 23-DOGS), presented for brief exposures titrated to maintain below-ceiling performance throughout practice. Participants reported strategy use (e.g., rote repetition, imagery) after each test. Substantial IAV in strategy use was detected that was coupled with performance; lists studied with normatively effective strategies (e.g., imagery) generated higher PA recall than lists studied with less effective strategies (e.g., rote repetition). In comparison to younger adults, older adults' practice (a) relied more on repetition and less on effective strategies, (b) showed lower levels of IAV in effective strategy use, and (c) had lower within-person strategy-recall coupling, especially late in practice. Individual differences in pretest-posttest gains in PA recall were predicted by average level of effective strategy use in young adults but by strategy-recall coupling in older adults. Results are consistent with the hypothesis that experiencing variability in strategic outcomes during practice helps hone the effectiveness of strategic encoding behavior, and that older adults' reduced degree of pretest-posttest gains is influenced by lower likelihood of using and optimizing effective strategies through practice.
\end{abstract}

Keywords: practice, strategy use, intraindivual variability, associative recall

Learning new associations is often aided by the use of mediational strategies, such as interactive imagery or sentence generation, to create new links between normatively unrelated concepts such as words or pictures (Paivio, 2007; Richardson, 1998). Use of encoding strategies to mediate new associations can be seen as a particular instantiation of how metacognitive self-regulation can improve performance across a range of cognitive tasks (e.g., Bjork,
Dunlosky, \& Kornell, 2013; Stine-Morrow, Miller, \& Hertzog, 2006; Winne, 1996). Developmental changes in the use of mediational strategies covary with memory improvements in children (see reviews by Hertzog \& Shing, 2011; Ornstein \& Light, 2010). In adult development, age-related deficits in spontaneous production of mediators have been observed but do not account for much variance in age-related associative memory decline (e.g., Dunlosky
This article was published Online First June 1, 2017.

Christopher Hertzog, School of Psychology, Georgia Institute of Technology. Martin Lövdén, Center for Lifespan Psychology, Max Planck Institute for Human Development, Berlin, Germany; Aging Research Center, Karolinska Institutet; and Department of Psychology, Stockholm University. Ulman Lindenberger, Center for Lifespan Psychology, Max Planck Institute for Human Development. Florian Schmiedek, Center for Lifespan Psychology, Max Planck Institute for Human Development, and German Institute for International Educational Research (DIPF) Frankfurt am Main, Frankfurt-am-Main, Germany.

Data reported in this article regarding strategy use and performance in the number-noun paired-associate task from COGITO have not been published elsewhere. A version of this work was presented by Christopher Hertzog at a conference on the COGITO project hosted in Berlin, Germany by the Max Planck Institute for Human Development, Berlin, on October 4, 2016.
The COGITO Study was supported by the Max Planck Society, including a grant from the innovation fund of the Max Planck Society (M.FE.A.BILD0005); the Sofja Kovalevskaja Award (to Martin Lövdén) of the Alexander von Humboldt Foundation donated by the German Federal Ministry for Education and Research (BMBF); the German Research Foundation (DFG; KFG 163); and the German Federal Ministry for Education and Research (BMBF; CAI). Ulman Lindenberger was supported by the 2010 Gottfried Wilhelm Leibniz Award of the DFG. This work benefitted from multiple visits by Hertzog to the Max Planck Institute for Human Development, Berlin as a Visiting Scientist.

Correspondence concerning this article should be addressed to Christopher Hertzog, School of Psychology, Georgia Institute of Technology, 654 Cherry Street Northwest, Atlanta, GA 30332-0170. E-mail: christopher.hertzog@psych.gatech.edu 
\& Hertzog, 2001; Shing, Werkle-Bergner, Li, \& Lindenberger, 2008; Tournier \& Postal, 2011; see Kausler, 1994, for a review of earlier studies). Older adults still manifest associative memory deficits when mediator production is manipulated through instructions, extended practice, or training (e.g., Brehmer, Shing, Heekeren, Lindenberger, \& Bäckman, 2016; Shing et al., 2008; Kliegl, Smith, \& Baltes, 1989). In single-session experiments, old age is associated with impairments in access at test to high-quality mediators generated at study (Dunlosky, Hertzog, \& Powell-Moman, 2005; Hertzog, Fulton, Mandviwala, \& Dunlosky, 2013), which suggests some role for postencoding mechanisms such as consolidation, controlled retrieval deficits, and/or encoding-retrieval interactions (e.g., Luo \& Craik, 2009) in age-related memory deficits. Shing et al. (2008) argued that such evidence speaks to the importance of associative binding and retrieval mechanisms (see also Old \& Naveh-Benjamin, 2008).

Although strategic behavior per se does not account for age differences in associative memory, it is clear that (a) individual differences in spontaneous (uninstructed) mediator production for new associations are observed in older adults (Bailey, Dunlosky, \& Hertzog, 2009; Dunlosky \& Hertzog, 1998); (b) all adults benefit from producing mediators (relative to using no strategy or ineffective strategies like rote repetition); (c) extended practice on episodic memory tasks (but without explicit strategy training) improves older adults' memory (e.g., Baltes, Sowarka, \& Kliegl, 1989); and (d) training older adults in effective strategy use such as interactive imagery enhances their associative memory performance relative to untrained older controls (e.g., Brehmer et al., 2016; Gross \& Rebok, 2011; Shing et al., 2008; Verhaeghen \& Marcoen, 1994). Thus, failure to produce mediators under typical unsupervised task conditions can inflate age-related effect sizes in associative memory (Dunlosky et al., 2005). Similar conclusions can be drawn about age differences in encoding strategies in other episodic memory tasks. In particular, older adults benefit from spontaneous use of relational and item-specific encoding strategies in list learning contexts (e.g., Hertzog, McGuire, \& Lineweaver, 1998; Jennings, Webster, Kleykamp, \& Dagenbach, 2005; Saczynski, Rebok, Whitfield, \& Plude, 2007) and training in organizational and relational encoding processes boosts older adults' free recall memory performance (e.g., Neely \& Bäckman, 1995; West, Bagwell, \& Dark-Freudeman, 2008).

It is surprising that memory training studies typically do not directly measure strategy use during memory task performance, relying solely on performance improvements to infer changes in the effectiveness of trained strategic behavior. Explicit self-report measures of strategy use predict individual differences in training benefits, implicating individual differences in the degree and quality of implementing trained strategies at posttest (e.g., Bailey, Dunlosky, \& Hertzog, 2014). Furthermore, Bailey and colleagues (2014) demonstrated that a failure of transfer from trained relational strategies in free recall to an associative recall task was accompanied by reported increases in strategy use in the associative task without apparent benefit. This outcome suggested that the failure to transfer was due to an unsuccessful attempt to adapt the trained strategy to a new task context (see Bottiroli, Cavallini, Dunlosky, Vecchi, \& Hertzog, 2013). Thus it is important to establish the conditions under which people do and do not implement encoding strategies in intensive practice and training contexts rather than assuming that training invariably increases the frequency, quality, and effectiveness of strategy use.

Developmental psychologists have evaluated how strategies grow and develop in children, uncovering fascinating evidence about strategy inconsistency and variability (e.g., Siegler, 2006). Young children's' variable strategy use in various arithmetic task contexts is positively correlated with subsequent task performance (Siegler, 1999, 2007; Siegler \& Lemaire, 1997). In fact, fixation on a single strategy or a relatively inflexible use of strategies for solving arithmetic problems is generally found to be maladaptive (Siegler, 1999); instead, use of multiple strategies may even be required to assess the relative benefits of alternative strategic approaches (Hinault, Dufau, \& Lemaire, 2015; Luwel, Foustana, Onghena, \& Verschaffel, 2013; Siegler \& Chen, 2008).

In contrast, flexible cognitive strategy use in adulthood may decline as people grow older. Indeed, strategy repetition-defined as repeated use of the same strategy across trials (such as repeated rounding up vs. rounding down in mental arithmetic tasks when some items afford one strategy over the other) - is more common in older adults, perhaps due to cognitive resource costs for adaptive strategy selection (Lemaire \& Leclère, 2014). Older adults also show greater strategy switch costs in such tasks than younger adults (Ardiale \& Lemaire, 2012). Lemaire (2010) has speculated that age-related changes in strategic flexibility reflect age-related declines in executive functioning. Older adults do learn about the benefits of using effective mnemonic strategies like interactive imagery in list-learning tasks (e.g., Bieman-Copland \& Charness, 1994; Price, Hertzog, \& Dunlosky, 2008), although they may not necessarily adopt these more difficult strategies in future tests, despite having learned about their effectiveness (Brigham \& Pressley, 1988; Hertzog, Price, \& Dunlosky, 2012). On the other hand older adults do report using multiple mnemonic strategies on different items within the same list, suggesting at least some level of strategic adaptivity (Dunlosky \& Hertzog, 1998; Saczynski et al., 2007).

This study used data from a project in which younger and older adults practiced multiple cognitive tasks over 100 sessions to evaluate IAV in encoding strategy use. The COGITO study (Schmiedek, Lövdén, \& Lindenberger, 2010) included 101 younger and 103 older adults who practiced a battery of 12 cognitive tasks over one hundred daily sessions. Each session included three tasks of episodic memory: word list memory, object position memory, and number-noun paired associates. We focus in this paper on the paired associate (PA) number-noun task, in which 12 combinations of two-digit numbers and nouns in plural form were presented sequentially and participants were asked to recall the numbers when cued with the nouns presented in random order. After each recall test, individuals were prompted to report whether they had used one or more relevant mnemonic strategies (pictorial imagination, creating a story, building a sentence, using personal associations, rote rehearsal [repetition]) when encoding the new associations. This kind of retrospective report has been shown to predict individual differences in younger and older adults' associative and free recall performance (e.g., Bailey et al., 2009; Dunlosky \& Hertzog, 1998; Hertzog et al., 1998).

We address several research questions about practiced associative mnemonics. First, do younger and older adults both manifest IAV in strategy use? Second, does this IAV differ between these two age groups? There have been to date no studies of long-term 
IAV in self-reported mnemonic strategy use as people practice list-learning tasks. Hence we know essentially nothing about how different individuals' strategic behavior varies across occasions of practice. Studies of practice with associative mediators are rare and typically focus on experimentally controlled, repeated access to the same mediators (e.g., Crutcher \& Ericsson, 2000) rather than on evaluating spontaneous strategy use on new items. We expected to observe substantial IAV in effective strategy use in both age groups.

There is a growing literature on IAV in adult cognition that typically focuses on within-task variability (such as variance in response time (reaction time [RT] tasks); Hultsch, Strauss, Hunter, \& MacDonald, 2007). Within-task RT variability is typically greater in older adults and is often associated with poorer cognitive performance, an increased likelihood of cognitive decline, and neurological features including dopamine receptor depletion (e.g., Bielak, Hultsch, Strauss, Macdonald, \& Hunter, 2010; MacDonald, Hultsch, \& Dixon, 2008; MacDonald et al., 2008; Ram, Rabbitt, Stollery, \& Nesselroade, 2005). However, Schmiedek, Lövdén, and Lindenberger (2013) used COGITO data to demonstrate that the associative recall task used here, the noun-number task, manifested reliably greater IAV in younger adults, both within days and across blocks of practice. Allaire and Marsiske (2005) had previously reported a similar finding for intellectualability tests when IAV was evaluated across days of practice. They showed that variability around a practice-related improvement function for intelligence tests (especially their test of inductive reasoning) was positively associated with slope of the improvement with practice, possibly reflecting "active testing of new performance strategies" (p. 398).

Our third goal was therefore to determine whether the previously demonstrated IAV in associative memory performance in the COGITO study was predicted by (coupled with) IAV in the use of associative mnemonic strategies. As noted earlier, strategy use has been linked to individual differences in memory performance but between-person differences do not necessarily reflect relations existing at the level of within-person changes (Molenaar, 2004; Voelkle, Brose, Schmiedek, \& Lindenberger, 2014). Memory performance is known to vary within a person over days (e.g., Hertzog, Dixon, \& Hultsch, 1992; Salthouse, Nesselroade, \& Berish, 2006; Sliwinski, Smyth, Hofer, \& Stawski, 2006), and specifically has been shown to vary in the COGITO study's PA task (Schmiedek et al., 2013). Such variability has never been empirically linked to intraindividual variability in strategic encoding behavior.

We hypothesized there would be reliable coupling of intraindividual variability between PA recall and reported use of effective mnemonics in the COGITO PA task. More specifically, we hypothesized (a) a significant fixed effect of such a coupling, indicating the average effect of using effective strategies, contrasted against not doing so, across blocks, (b) a significant random effect of this coupling, indicating between-person differences in the strength of the effect of using effective strategies, which (c) can partly be explained by age group, because of older adults, on average, profiting less from the implementation of mnemonic strategies. Such expectations would be consistent with the agecomparative training literature.

Fourth, we asked whether average level of strategy use and coupling of strategy-recall IAV during practice predicts long-term memory performance improvements. The study design included an initial pretest on an associative memory task prior to the 100 sessions of practice, which were then followed by a parallel posttest. Earlier analyses of COGITO data have shown that both age groups significantly improved their performance on the associative memory task from pretest to posttest after the 100 sessions of practice (Schmiedek, Bauer, Lövdén, Brose, \& Lindenberger, et al., 2010). Given (a) demonstrated benefits of mnemonic strategies for associative memory and (b) evidence that strategy training improves adults' episodic memory performance, we hypothesized that individuals using effective strategies most frequently during practice would perform best on the memory pretest, reflecting the benefits of a stable disposition toward effective mnemonics usage for improving strategy use effectiveness with practice. However, we were even more interested in evaluating whether the degree to which individual differences in the degree of strategy-recall IAV coupling during practice relates to pretest-posttest performance improvements. The developmental literature on strategy adaptivity reviewed earlier would predict that greater IAV in strategy use during practice reflects a process of strategic discovery in the associative memory task environment that (a) generates better metacognitive control over strategy selection and implementation (see Hertzog, 2016) during practice, and (b) thereby leads to greater performance gains from pretest to posttest.

\section{Method}

\section{Participants and Procedure}

During the daily assessment phase of the COGITO Study, 101 younger adults (51.5\% women, age: $20-31$ years, $M=25.6, S D=$ 2.7 ) and 103 older adults (49.5\% women, age: $65-80$ years, $M=$ $71.3, S D=4.1$ ) completed an average of 101 practice sessions. Both younger and older samples were quite representative regarding general cognitive functioning, as indicated by comparisons of Digit-Symbol performance with data from a population-based study and a meta-analysis (Schmiedek et al., 2010), and showed positive selectivity of comparable size regarding self-rated health (Wolff et al., 2012). Attrition rate for those participants who had entered the longitudinal practice phase was low (for details on rates and reasons of dropout in the different study phases, see Schmiedek et al., 2010).

Participants practiced individually in lab rooms containing up to six computer-testing places. Before and after this longitudinal phase, participants completed pre- and posttests during 10 sessions that consisted of $2-2.5 \mathrm{~h}$ of comprehensive cognitive test batteries and self-report questionnaires. On average, the time that elapsed between pre- and posttest was 197 days for the younger and 188 days for the older group.

Participants were paid between 1,450 and 1,950 Euro, depending on the number and temporal density of completed sessions. The ethical review board of Max Planck for Human Development, Berlin, approved the study.

In each practice session, participants practiced 12 different tasks drawn from a facet structure cross-classifying cognitive abilities (perceptual speed, episodic memory, and working memory) and content material (verbal, numerical, figural-spatial) with two to eight blocks of trials each (for information on all practiced tasks, see Schmiedek et al., 2010). 


\section{Measures}

PA task at pretest and posttest. A list of 12 two-digit numbers paired with nouns in plural case (e.g., "23 dogs") were presented sequentially during each pretest and posttest task block. The ISI between presented words was $1 \mathrm{~s}$. Nouns were drawn randomly from a set of 415 nouns. All nouns were two-syllable words of low frequency (0-19 entries per million in the CELEX word frequency database; Baayen, Piepenbrock, \& Gulikers, 1995), of high imageability (Mean rating $=85.9 ; S D=4.7$; Range $=76.5$ to 95.7 , on a 0 to 100 imagery scale in the word rating study by Grandy, Lindenberger, \& Schmiedek, 2016) and positive valence (Mean rating $=17.5 ; S D=11.2$; Range $=-3.9$ to 41.8 , on the -100 to +100 imagery scale; see Grandy et al., 2016). Nouns were drawn randomly from a set of 415 nouns with the constraint that they were used only once at pretest or at posttest. Numbers for the PA items were selected at random from the set of possible two-digit numbers (10-99, excluding numbers with repeating elements, e.g., 22, 33). Participants first worked on 12 blocks (lists) of practice, with decreasing presentation time (8 $\mathrm{s}$ [3 blocks], $4 \mathrm{~s}$ [3 blocks], $2 \mathrm{~s}$ [3 blocks], and $1 \mathrm{~s}$ [3 blocks]). Then, they did 24 test blocks with presentation time decreasing and increasing again ( $8 \mathrm{~s}$ [3 blocks], $4 \mathrm{~s}$ [3 blocks], $2 \mathrm{~s}$ [3 blocks], $1 \mathrm{~s}$ [6 blocks], $2 \mathrm{~s}$ [3 blocks], $4 \mathrm{~s}$ [3 blocks], and $8 \mathrm{~s}$ [3 blocks]). This same schedule of 24 test blocks was repeated at posttest. At test, all numbers had to be entered based on noun prompts in a randomly selected order. Performance was scored as the logit-transformed percentage of correct numbers. In analysis of pretest and posttest data, presentation time is treated as a within-subjects factor.

PA lists during practice sessions. Two lists were included in each daily session. To keep participants' performance levels from floor and ceiling across the 100 daily sessions, presentation time was adjusted individually based on pretest performance and fixed at the individual levels across the daily practice sessions for the working memory and episodic memory tasks. Lists of 12 two-digit numbers paired with nouns in plural case (e.g., "23 dogs") were presented sequentially with people assigned to receive presentation times of either 1, 2, or 4 seconds. Assignment to presentation time condition was based on results of exponential time-accuracy functions (with free parameters for onset, rate, and asymptote) fitted to each participant's pretest data. Based on the fitted function, the individual presentation time for the daily sessions (either 1, 2, or 4 seconds) was chosen so that accuracy was above .25 and below .50 . If predicted accuracy was above .50 for the 2 -s condition, then a presentation time of one second was chosen, even if predicted accuracy for this condition was below .25. This procedure resulted in individual presentation times of 1 second for 35 younger and two older, of 2 seconds for 22 younger and 14 older, and of 4 seconds for 44 younger and 87 older participants, respectively.

The general procedures for list construction and practice task presentation were identical to pretest and posttest conditions. Nouns for each 12-item block were selected at random from the set of 415 nouns with the constraint that no noun could used more frequently than once in a set of seven lists; numbers were selected at random from the eligible set. The ISI was maintained at $1 \mathrm{~s}$, and recall for each list was tested with a random order of presented numbers as recall cues.

Strategy questionnaire. In the daily practice sessions, after each block of the PA task, participants completed a brief strategy questionnaire presented at the computer. They were asked to indicate whether or not they used any of the following strategies: (a) pictorial imagination ("Did you create a visual image of the number-noun combination?"), (b) creation of a story ("Did you try to combine the number-noun combinations into a story?"), (c) creation of sentences ("Did you try to create one or more sentences that include the number-noun combinations)"), (d) personal associations ("Did you use a particular personal association that came to your mind regarding the number-noun combination?"), or (e) rote rehearsal ("Did you try to remember the number-noun combinations by silent rehearsal?"). Participants could select more than one of these response options. Participants could also indicate that they had used some other strategy and enter a description of it as free text. This latter option was chosen only rarely (on $3 \%$ of the total number of blocks) and on $16 \%$ of the blocks where it was chosen, no free text was entered. Of the remaining blocks with free text answers, $91 \%$ were provided by 8 younger adults with highly consistent use of particular strategies (e.g., use of year dates, coding scheme associating single digits with objects). Use of idiosyncratic meaning can be an effective associative mnemonic, but we had no easy basis for evaluating whether this was indeed the case. These specific instances were treated as missing data in the analyses, and were not considered further. If anything, this decision would bias the findings against younger adults' being rated as using effective strategies.

The principal measure of mnemonic strategy use for this study was a derived measure of effective strategy use, generated by coding the report of at least one of the four strategies that used imagination, association, or organization together as an instance of effective strategy use (scored with 1 if at least one of the effective strategies was used, and 0 otherwise). This type of index has been successfully used in other self-report strategy use studies (e.g., Bailey et al., 2009).

\section{Data Analysis}

As a general framework for analyzing within-person variations and couplings of strategy use and memory performance, as well as their relations to between-person differences in long-term improvements, two-group (younger and older adults) two-level structural equation models, as implemented in Mplus 7 (Muthén \& Muthén, 2012) using maximum likelihood estimation were employed. Level 1 represented each instance of administration of the PA task and strategy questionnaire. Level 2 corresponded to individuals nested within the two age groups. The statistical models specified fixed and random effects across the random effects factor of persons. Hence we could evaluate age differences in average use of effective strategies and how strategic behavior changed over blocks of practice; we could also estimate intraindividual variability in effective strategy use (capturing fluctuations across task instances with practice). Likewise, we could evaluate age differences in the extent to which these effects were coupled by specifying within-person (Level 1) regressions of memory performance on effective strategy use. Configurations of parameters of interest were tested using likelihood ratio tests and considered significant when $p<.05$. Age differences in parameters were evaluated with likelihood ratio tests applied to comparisons of models with and without equality constraints for the parameter of interest across age groups. 


\section{Results}

\section{Age Differences in Strategy Use Across Practice}

Figure 1 shows average reported use of the different strategies across the 100 daily sessions for the two age groups. Older adults used the alterative effective strategies less often than younger adults, but were more likely to employ rote rehearsal (repetition). The aggregate measure of effective mnemonic use revealed that younger adults used these strategies more often than older adults (see Figure 2). To quantify this effect, we ran a two-level logistic regression model with cumulative block number (from 1 to 200, for the 100 sessions with 2 blocks each; rescaled to a range from 1 to 10 for parameter estimation) as within-person and age group as between-person predictor variables of effective strategy use (as a binary dependent variable), respectively, specifying random effects on intercepts (individual differences in aggregate strategy use). The model revealed significant age-related effects on level, $\beta=-1.98, S E=0.19, \chi^{2}(1)=12.11 ; p<.05$, and on the average trend across sessions, $\beta=-0.57, S E=0.14, \chi^{2}(1)=17.63 ; p<$ .05 , with older adults' use of effective strategies being lower and declining more over the course of the study. Both level and trend were also predicted significantly by presentation time, $\beta=-0.99$, $S E=0.10, \chi^{2}(1)=20.58 ; p<.05$, for level, and $\beta=-0.17$, $S E=0.06, \chi^{2}(1)=10.05 ; p<.05$, for trend, respectively, with slower presentation times being associated with less use of effective strategies. As age group and presentation time condition were correlated (i.e., younger adults tended to more often get assigned to faster presentation time conditions than older adults), we also considered both predictor variables simultaneously. Regarding level of effective strategy use, this resulted in a significant negative effect of presentation time, $\beta=-0.90, S E=0.10, \chi^{2}(1)=10.35$; $p<.05$, but no reliable effect of age group, $\beta=-0.67, S E=$ $0.20, \chi^{2}(1)=2.61$, whereas for the practice-related trend, the reverse pattern emerged, with age group, $\beta=-0.48, S E=0.15$, $\chi^{2}(1)=10.54 ; p<.05$, but not presentation time, $\beta=-0.08$, $S E=0.06, \chi^{2}(1)=1.82$, being significant. Even after accounting

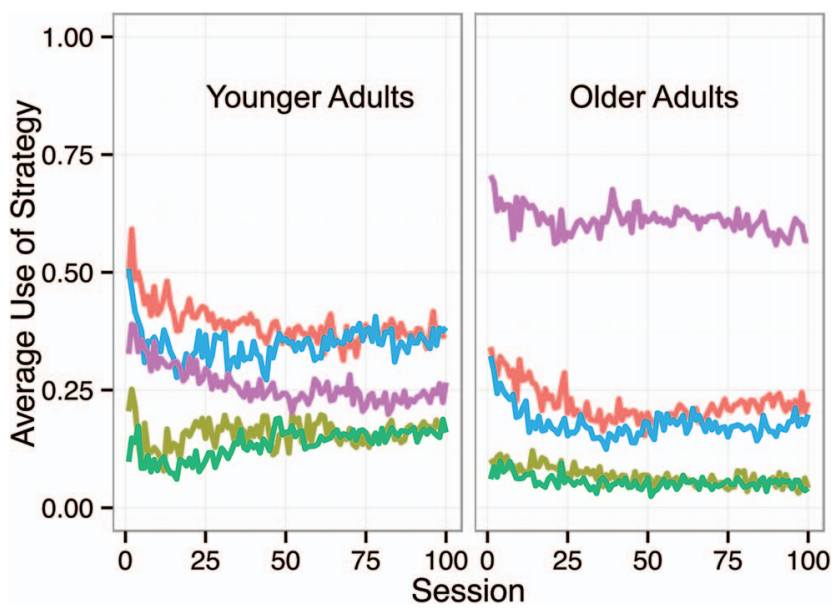

Figure 1. Average proportion of use of different strategies across 100 daily sessions. Magenta line = rehearsal; red line = pictorial imagination; blue line $=$ personal associations; olive green line $=$ creation of a story; petrol green line $=$ creation of sentences.

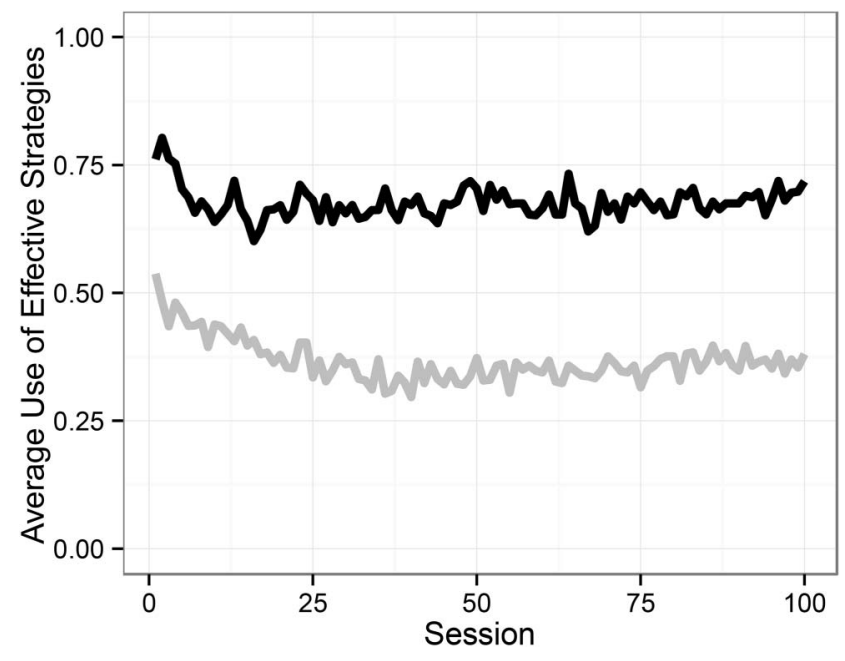

Figure 2. Average proportion of use of effective strategies across 100 daily sessions. Black line $=$ younger adults, Grey line $=$ older adults.

for age group and presentation time, random effects for the level and trend were still highly significant (level: $\sigma^{2}=11.91, S E=$ 0.36; trend: $\left.\sigma^{2}=0.73, S E=0.13\right)$, indicating substantial individual differences in the use of effective strategies. ${ }^{1}$

Given the binary effective strategy measure, there is a statistical dependence of each person's mean strategy use and their withinperson variance in effective strategy use; that is, if $p=$ probability of an effective strategy and $q=$ probability of no effective strategy, then the intraindividual $M=p$ and the intraindividual $S D=$ $(p q)^{.5}$. Arguably, then, the best estimate of IAV in each age group is the estimated residual variance for a multilevel logistic regression model, controlling for all predictors (e.g., Block) included in the previous model, since this controls for mean level and average trend over time. Using SAS PROC GLIMMIX (SAS Institute Inc., 2008), we estimated the residual IAV for young adults to be 0.278 $(S E=.0028)$, with a lower corresponding value of .257 ( $S E=$ .0028) for older adults. Both residual variances were reliably greater than zero, and younger adults' estimated IAV was significantly higher than older adults' estimated IAV, $\chi^{2}(1)=31.90$, $p<.001$.

One reason for older adults' reduced IAV in effective strategy use may be their consistent reliance on the rote rehearsal strategy (see Kausler, 1994). Being in the older group was associated with significantly higher levels of rote rehearsal use, $\beta=2.28, S E=$ $0.50, \chi^{2}(1)=19.57 ; p<.05$, and less decline in use of the repetition strategy across sessions, $\beta=0.43, S E=0.14, \chi^{2}(1)=$ 9.57; $p<.05$. The same was true for higher presentation times, $\beta=1.14, S E=0.09, \chi^{2}(1)=24.90 ; p<.05$, for level, and $\beta=$ $0.15, S E=0.06, \chi^{2}(1)=5.39 ; p<.05$, for the trend across sessions. When considering both predictors simultaneously, the effects of age group remained significant, $\beta=1.35, S E=0.54$,

\footnotetext{
${ }^{1}$ Figures 1 and 2 suggest practice-related curvature in strategy use, with an early reduction in strategy use over the first 20 practice blocks. Any such effect is apparently small in magnitude; we tested for a quadratic effect and found none, as well as no reliable age difference in the quadratic trend.
} 
$\chi^{2}(1)=5.92 ; p<.05$, for level, and $\beta=0.34, S E=0.16, \chi^{2}(1)=$ $4.76 ; p<.05$, for the trend across sessions, whereas presentation time only had an effect on level $\left(\beta=0.82, S E=0.22, \chi^{2}(1)=\right.$ 12.99; $p<.05$, but not on the trend, $\beta=0.08, S E=0.06, \chi^{2}(1)=$ 1.51. Again, random effects of level and trend were highly significant (level: $\sigma^{2}=11.03, S E=1.24$; trend: $\sigma^{2}=0.77, S E=0.13$ ). In sum, older adults in our study seem more inclined to use and maintain their use of the simple repetition strategy.

Overall, older adults were either reluctant or less able to use effective strategies and more likely to rely on the less effective rote rehearsal strategy. This pattern occurred despite the fact that older adults were more likely to be assigned to slower presentation time conditions for practice lists based on pretest performance, which actually provided them with more time to implement more demanding mnemonic strategies. In general, within-person manipulations of presentation time in PA learning produce positive effects, with increasing presentation time increasing both mnemonics use and benefits PA recall (see Kausler, 1994). It therefore seems likely that the negative effects of (between-subjects assigned) presentation time found here (slightly lower use of effective strategies at longer presentation times) reflected a masked effect of individual differences in underlying memory abilities, given that lower-performing individuals at pretest were assigned to longer presentation time conditions. The observed age differences conformed to expectations from previous literature finding older adults to be less likely to use associative mnemonics for these kinds of difficult PA items (Kausler, 1994). Furthermore, although older adults did manifest reliable residual IAV in effective strategy use, the residual IAV index we generated was greater in the younger adult group, consistent with the conjecture by Allaire and Marsiske (2005).

\section{PA Recall Changes With Practice}

Schmiedek et al. (2013) previously reported on age group differences in PA recall performance and in PA recall IAV during practice. Younger adults had higher levels of recall and manifested higher levels of IAV (a pattern also observed for other cognitive tasks in the COGITO test battery). Here we report only the basic pattern of effects relevant to our hypotheses about coupling of these effects with strategy use and about links between practice changes in recall and pretest-posttest gains. The fixed effects of Block were significant for both younger, $\chi^{2}(1)=49.06 ; p<.05$, and older adults, $\chi^{2}(1)=31.38 ; p<.05$, showing practice-related gains in recall performance. The difference between the two groups in practice improvements was not significant, $\chi^{2}(1)=0.19$. The random effects for the Block were significant in both age groups $\left(\sigma^{2}=0.024 ; S E=0.003\right.$, for younger, and $\sigma^{2}=0.009$; $S E=0.001$, for older participants), indicating reliable individual (between-person) differences in the slope of PA recall improvement over blocks. This variance component was reliably greater in younger adults, $\chi^{2}(1)=23.18 ; p<.05$, demonstrating more between-person variability in practice-related recall improvement in younger adults.

\section{Within-Person Couplings of Strategy Use and Performance}

We evaluated coupling of within-person changes and fluctuations in effective strategy use and recall performance in the number-noun PA task performance across the 200 task blocks (i.e., 100 sessions with 2 blocks each; rescaled to a range from 1 to 10 for parameter estimation) by running two-group (younger and older adults) two-level models with Block and dummy-coded (effective) Strategy Use $(0=n o, 1=y e s)$ as predictors of PA recall at the within-person level (Level 1). Fixed effects of these two predictors represented average improvements across the 100 sessions and couplings of performance fluctuations (around the long-term trend) with use of effective strategies, respectively. Random effects of both predictors were also included, representing between-person differences (Level 2) in long-term changes as well as in the strength of the coupling of strategy use and performance.

The average coupling of use of effective strategies and blockwise performance was significant for both younger, $\chi^{2}(1)=32.65$; $p<.05$, and older adults, $\chi^{2}(1)=63.37 ; p<.05$. These regression coefficients differed between age groups, $\chi^{2}(1)=11.63 ; p<.05$. Younger adults demonstrated a much stronger coupling effect (i.e., $\beta=.85, S E=.10$, vs. .42, $S E=0.07)$. Use of effective strategies was reliably associated with greater PA recall during practice.

We also tested whether the coupling of use of effective strategies with performance was moderated by Block, that is, whether there was a trend for increasing or decreasing strength of the coupling over the course of the training. For the younger adults, this interaction was significant, $\beta=.058, S E=.026, \chi^{2}(1)=$ 4.89. The predicted coupling strength doubled from .57 at the beginning to 1.14 at the end of the study. For the older adults, the interaction was not significant, $\chi^{2}(1)=0.46$, nor was there a significant age group difference in the strength of the interaction, $\chi^{2}(1)=0.11$. For both age groups, however, reliable individual differences in the strength of the interaction were found, as indicated by significant random effects for younger adults, $\chi^{2}(4)=$ 43.50, and older adults, $\chi^{2}(4)=15.14$.

Using the estimated model parameters we generated predicted scores that reflected within-person performance benefits of coupling early and late in practice. When a younger adult used an effective strategy on a list (relative to when they did not) they realized a $16 \%$ recall enhancement at the beginning of training and a $21 \%$ recall enhancement at the end of training. On average, an older adult also realized a recall benefit, but one that was much smaller-only $6 \%$ at the beginning and $9 \%$ at the end of practice, respectively. Clearly IAV in effective strategy use during practice had a much larger effect on associative recall for the younger adults. This effect probably reflects the production of higher quality mnemonics by younger adults, especially after extended practice. It is interesting to note that random effects for Strategy Use coupling effects were also significant for both age groups, with a larger variance for the younger than for the older adult group (younger adults: $\sigma^{2}=0.905 ; S E=0.144$; older adults: $\sigma^{2}=$ $0.254 ; S E=0.049$ ); rejecting the null hypothesis of equal agegroup variances, $\chi^{2}(1)=24.86 ; p<.05$. This outcome suggests that IAV in strategy use has stronger effects on recall performance for some individuals than for others, perhaps reflecting systematic between-person differences in the origins and quality of implementing normatively effective strategies across blocks of practice.

In summary, these analyses show that variation in effective strategy use across lists was a significant predictor of associative recall for both age groups. For those lists where individuals reported using an effective strategy, they garnered better recall performance. This effect was much stronger for younger adults. In 
addition, younger adults showed stronger coupling effects later in practice, whereas older adults did not. Moreover, despite extended practice individuals within both age groups varied reliably in the magnitude of these coupling effects.

\section{Relations of Practice-Related Strategy Use and Strategy-recall Coupling to Pretest and Postest Recall}

Next, we investigated changes in performance from pretest to posttest and whether individual differences in these changes were related to individual differences in (a) the use of effective strategies, and/or (b) the strength of couplings of strategy use with performance during the training sessions. Furthermore, we wanted to investigate to which degree such individual differences were associated with age.

These questions could be addressed using two-level structural equation models with a latent change score model (McArdle,
2009) for the pre-post changes at the between-person level (Level 2) combined with a regression model predicting daily performance with a long-term trend (i.e., block number) and use of effective strategies (coded as a dummy) as predictor variables at the withinperson level (Level 1). In these models, random effects of level, slope of the trend across 100 sessions, and the coupling of strategy use and performance at the block-to-block level could be used as predictor variables of individual differences in pre-post changes at the between-person level. Figure 3 illustrates this model.

This two-level structural equation model enabled us to estimate individual differences in the use and effectiveness of strategies during practice as predictors of individual differences in pretestto-posttest performance improvements. Specifically, performance level at pretest was used to predict between-person differences in (a) the average use of effective strategies (person means), (b) the practice-related trend across the 100 sessions (random effect of

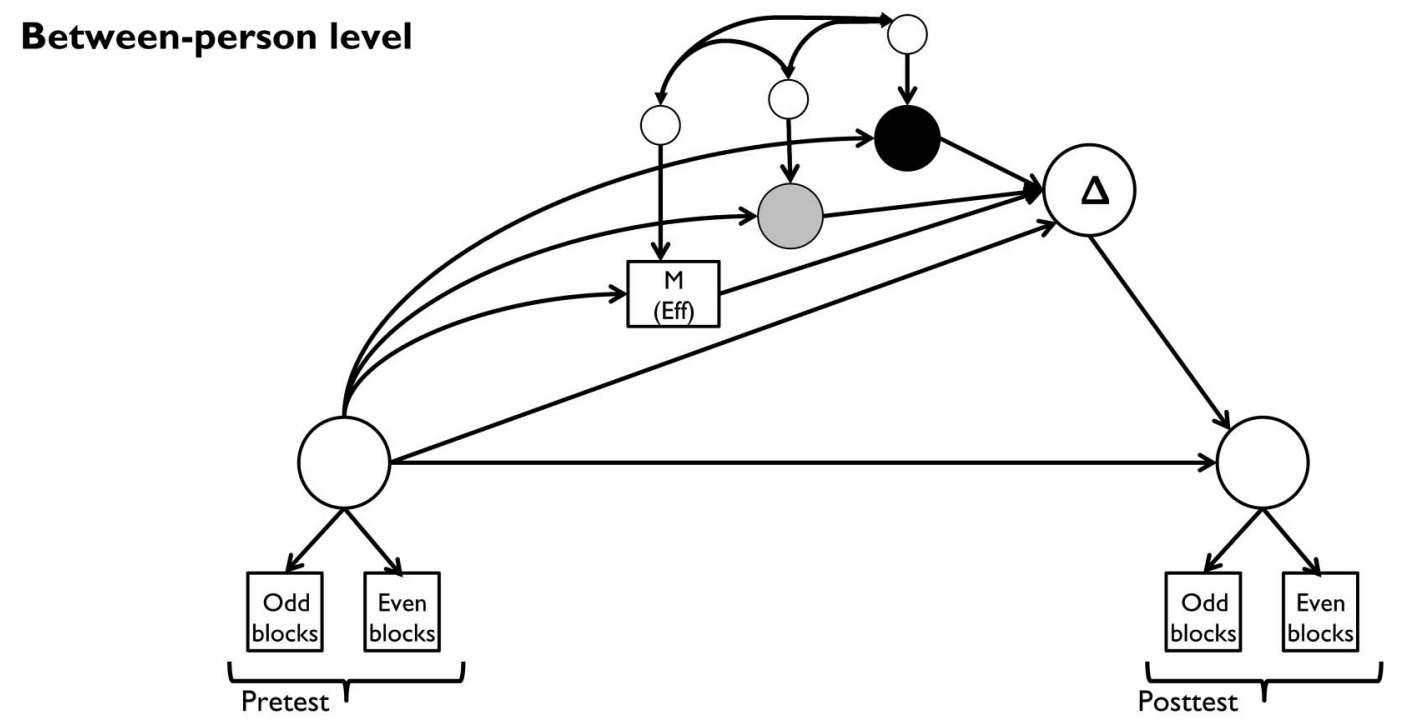

Within-person level

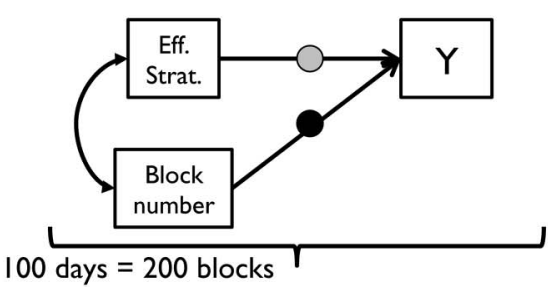

Random coupling of performance (Y)with effective strategy use

Random trend

Figure 3. Schematic representation of the two-level structural equation model for the combined analysis of daily within-person processes and long-term changes from pretest to posttest. At the within-person level, performance $(\mathrm{Y})$ on single blocks of the paired associates task across the 100 daily training sessions is predicted by cumulative block number, to account for practice-related improvements, and by block-to-block variations in the use of effective strategies (dummy-coded; person-mean centered). At the between-person level, a latent change score model is used to represent changes in performance from pretest to posttest. Latent factors are defined by composite scores of odd and even blocks of the presentation time condition analyzed. Strong measurement invariance is imposed across occasions and age groups. The mean and variance of the latent change score factor $(\Delta)$ represents average practice-related change and individual differences therein. The grey circles denote the random effect of the trend at the day-to-day level (i.e., individual differences in change across the 100 sessions). The black circles denote the random effect of effective strategy use on performance on single blocks (i.e., individual differences in the strength of the coupling of strategy use and performance). Both random effects are included as latent variables, together with person means of effective strategy use, at the between-person level to predict individual differences in pre-post changes. 
Block), and (c) the strength of the within-person coupling of effective strategy use and performance on single blocks (random effect of Strategy Use on performance). These three variables in turn had direct paths on the latent change score factor measuring change from pretest to posttest in PA recall. We specified a two-group model for the younger and older adults separately for each presentation time condition, given differences in presentation times for different people during practice. These two-group models permitted tests of age-group differences in the relationships depicted in Figure 3.

Pretest-posttest changes in PA recall. In a first set of analyses, average performance changes from pretest to posttest (see Table 1, for descriptive statistics), as well as individual and age group differences therein, were investigated with latent change score models. All persons received equivalent presentation times at both pretest and posttest (see Methods), but had experienced only one presentation time condition during practice. Hence, analyses were done separately for each of the four different presentation time conditions at pretest and posttest. Latent factors for and posttest scores were created using composites of odd- and evennumbered blocks as indicator variables. Strict measurement invariance was imposed; that is, factor loadings, intercepts, and residual variances of the indicator variables were constrained to be equal across occasions as well as across age groups. This resulted in acceptable model fit with the exception of the RMSEA being above conventional cut-offs for good model fit at presentation times of $1 \mathrm{~s}$ and $8 \mathrm{~s}$-presentation time $=1 \mathrm{~s}: \chi^{2}(14)=38.25$; RMSEA $=.13 ; \mathrm{CFI}=.94 ; \mathrm{SRMR}=.06$; presentation time $=2 \mathrm{~s}$ : $\chi^{2}(14)=23.84$; RMSEA $=.08$; CFI $=.98$; SRMR $=.05$; presentation time $=4 \mathrm{~s}: \chi^{2}(14)=23.20 ;$ RMSEA $=.08 ; \mathrm{CFI}=.98$; SRMR $=.05 ;$ presentation time $=8 \mathrm{~s}: \chi^{2}(14)=32.89$; RMSEA $=.12 ; \mathrm{CFI}=.97 ; \mathrm{SRMR}=.05$. For the interpretability and comparability of results, we decided to maintain the strict measurement invariance specification in all analyses.

Probing the significance of average performance changes from pretest to posttest by testing the hypothesis of zero mean latent change score improvement was rejected for all eight Age $\times$ Presentation Time conditions, $\chi^{2}(1)$ ranging from 32.56 to 72.59 , for the younger, and $\chi^{2}(1)$ ranging from 40.40 to 76.49 , all $p$ s $<$ .05 . Dividing the latent means by the $S D$ of the latent factor at pretest (pooled across younger and older adults) as a measure of effect size (ES) showed that the improvements after practice could be considered large (Cohen, 1988) for younger adults ( $E S=0.89$, 0.73, 0.83, 1.04; for presentations times of $1 \mathrm{~s}, 2 \mathrm{~s}, 4 \mathrm{~s}, 8 \mathrm{~s}$, respectively) and medium-sized for older adults ( $\mathrm{ES}=0.63,0.52$, $0.64,0.61$ ). Those numerical age-group differences in improvements were significant only for the slowest presentation time condition, however, $\chi^{2}(1)=13.43 ; p<.05$.

Pretest as a predictor of strategy use, recall improvements, and strategy-performance coupling during practice. We next evaluated whether pretest performance predicted the withinperson couplings of strategy use and performance improvements during practice. As reported in Table 2, between-person differences in pretest performance reliably predicted (a) the average use of effective strategies during practice and (b) degree of performance improvement across practice sessions. These effects were found for all presentation time conditions and for younger as well as older adults (with the exception of the effect of average strategy use at presentation time of $4 \mathrm{~s}$ in the older adults). Age group differences were not reliable, and the parameter estimates were very similar. Thus, for both age groups individuals performing better at the pretest baseline improved more during training and had higher average use of effective strategies.

We also evaluated whether pretest PA task performance predicted intraindividual coupling of strategy use and performance during practice. Individual differences in pretest recall performance were reliably related to individual differences in the degree of coupling of practice-related variability in strategy use and recall in both age groups, and none of the age comparisons were reliably different (see Table 2). Individuals performing higher at pretest (possibly due to the use effective strategies) show greater effects of variability in strategy use on recall during practice. This pattern indicates that the IAV in strategy use and recall during practice is positively predicted by pretest memory performance, and indi-

Table 1

Descriptive Statistics and Paired-Sample t Tests for Paired-Associate Task Performance at Pretest and Posttest Under Different Presentation Time Conditions

\begin{tabular}{|c|c|c|c|c|c|c|}
\hline \multirow[b]{3}{*}{ Presentation time } & \multicolumn{3}{|c|}{ Younger adults } & \multicolumn{3}{|c|}{ Older adults } \\
\hline & Pretest & Posttest & Difference pre-post & Pretest & Posttest & Difference pre-post \\
\hline & $M(S D)$ & $M(S D)$ & $t(100)$ & $M(S D)$ & $M(S D)$ & $t(102)$ \\
\hline \multicolumn{7}{|c|}{ Accuracy } \\
\hline $1 \mathrm{~s}$ & $.25(.18)$ & $.39(.25)$ & $7.86^{*}$ & $.12(.06)$ & $.18(.10)$ & $8.10^{*}$ \\
\hline $2 \mathrm{~s}$ & $.35(.22)$ & $.48(.28)$ & $6.73^{*}$ & $.17(.09)$ & $.23(.13)$ & $7.24^{*}$ \\
\hline $4 \mathrm{~s}$ & $.41(.25)$ & $.55(.30)$ & $7.10^{*}$ & $.19(.10)$ & $.30(.15)$ & $9.75^{*}$ \\
\hline $8 \mathrm{~s}$ & $.48(.26)$ & $.64(.29)$ & $8.83^{*}$ & $.27(.12)$ & $.41(.18)$ & $11.57^{*}$ \\
\hline \multicolumn{7}{|c|}{ Logit (accuracy) } \\
\hline $1 \mathrm{~s}$ & $-1.61(1.31)$ & $-0.74(1.70)$ & $6.67^{*}$ & $-2.62(0.92)$ & $-2.00(0.95)$ & $7.34^{*}$ \\
\hline $2 \mathrm{~s}$ & $-1.00(1.51)$ & $-0.16(1.98)$ & $5.98^{*}$ & $-2.17(1.02)$ & $-1.56(1.01)$ & $6.83^{*}$ \\
\hline $4 \mathrm{~s}$ & $-0.59(1.65)$ & $0.41(2.21)$ & $6.73^{*}$ & $-1.90(0.85)$ & $-1.12(0.97)$ & $9.75^{*}$ \\
\hline $8 \mathrm{~s}$ & $-0.04(1.78)$ & $1.33(2.31)$ & $10.26^{*}$ & $-1.26(0.85)$ & $-0.47(1.10)$ & $10.39^{*}$ \\
\hline
\end{tabular}

${ }^{*} p<.01$. 
Table 2

Effects of Individual Differences in Pretest Performance on Individual Differences in Process Parameters as a Function of Pretest Presentation Time

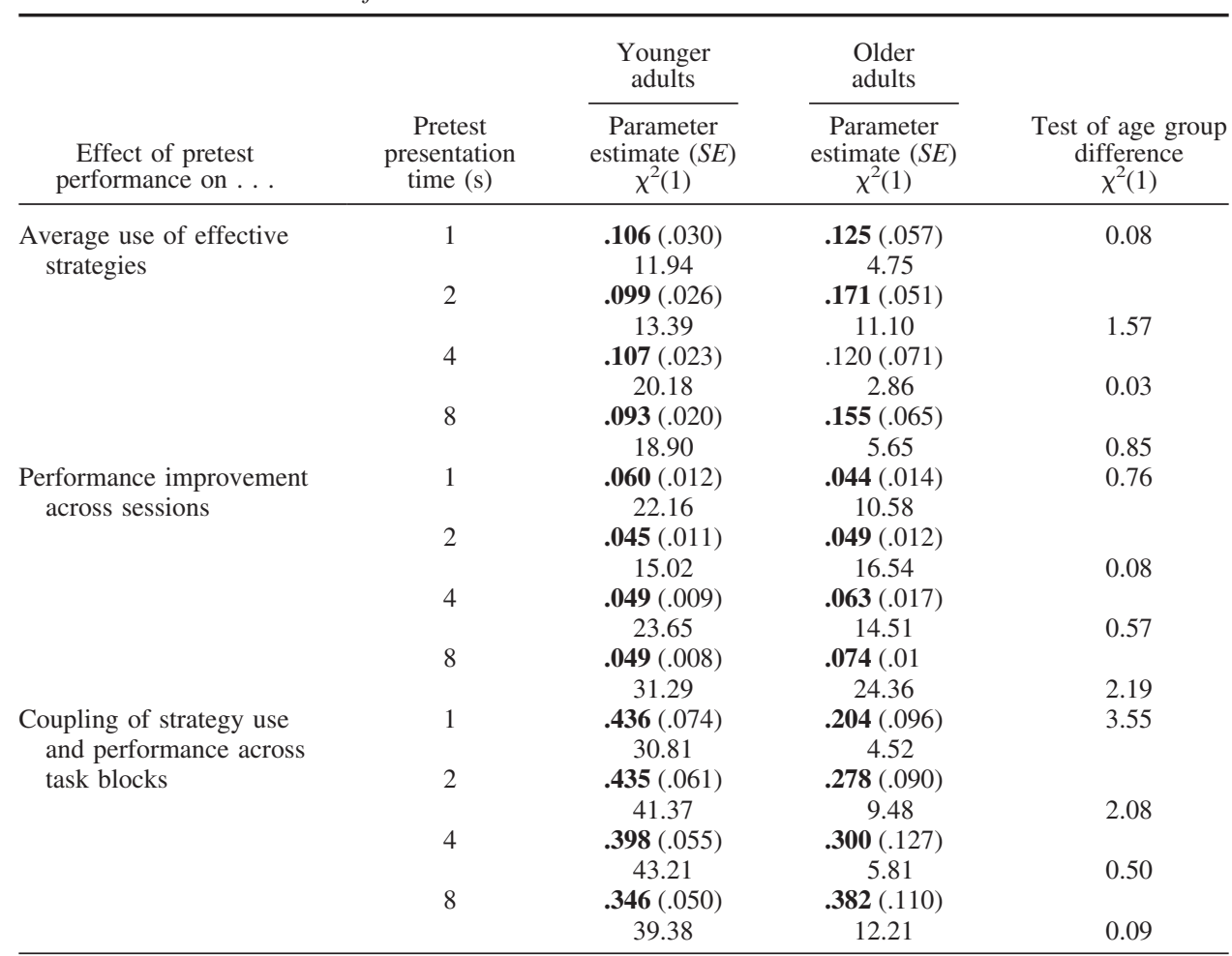

Note. Boldface indicates significant parameter estimates according to the chi-square test.

rectly, with the background intellectual abilities that predict gains in memory performance (see Schmiedek et al., 2010).

Average strategy use, recall improvements, and strategyperformance coupling as predictors of pretest-posttest improvements. Table 3 reports relationships of pretest and the three practice-related variables to pretest-posttest recall changes. The model included the prediction of gains by pretest performance to ensure that effects of practice variables could not be attributed to carry-over effects of pretest, so they are reported in Table 3, but are not of principal interest. There were, however, reliable effects of the practice-related variables. First, individual differences in average level of effective strategy use during practice predicted pretest-posttest improvements in younger adults for all but the fastest presentation rate of one second, but average effective strategy use did not predict recall improvements for older adults. The explicit tests of age differences were not reliable, however, so we cannot definitively argue for age differences in these relationships. Younger adults who on average used more effective strategies across practice sessions showed the largest performance gains at posttest. Second, larger improvements from pre- to posttest at all presentation times were reliably associated with greater gains in practice-related performance for younger adults, but not older adults, and in this case the age differences were statistically significant. Those younger adults showing the greatest practicerelated recall improvements also showed greater gains from pretest to posttest.

Third, a different pattern emerged for the parameter capturing practice-related coupling of strategies and recall performance dur- ing practice. Although the previous analysis showed that older adults had lower levels of intraindividual coupling in the aggregate, individual differences in coupling within the older group were reliably associated with pretest-posttest performance gains at two, four, and eight second presentation times. The opposite pattern was seen for younger adults, for whom individual differences in coupling during practice only predicted performance improvements for the fastest one second presentation rate.

Admittedly the age differences in effects need to be treated with some caution, given that the pattern of age differences in statistically significant effects was not accompanied with significant LR tests of age differences at any presentation time (see right-hand column of Table 3). Acknowledging this limitation, we interpret this pattern as indicating that, among younger adults, individual differences in training outcomes tended to be more strongly influenced by both (a) whether they were using effective strategies and (b) by aggregate practice-related recall improvements. For older adults, individual differences in posttest performance gains were greater when effective strategy use during practice led to better recall performance, relative to when effective strategies had not been used. Possible explanations of this pattern are considered below.

\section{Discussion}

Some of the effects observed in this study are broadly consistent with expectations from previous age-comparative studies of strategy use and memory. Older adults manifested lower levels of mean 
Table 3

Individual Differences in Latent Changes From Pretest to Posttest Predicted by Pretest Performance and Individual Differences in Practice-Related Variables as a Function of Posttest Presentation Time

\begin{tabular}{|c|c|c|c|c|}
\hline & Posttest & Younger adults & Older adults & \\
\hline Predictor & $\begin{array}{l}\text { Presentation } \\
\text { time }(\mathrm{s})\end{array}$ & $\begin{array}{l}\text { Parameter estimate } \\
(S E) \chi^{2}(1)\end{array}$ & $\begin{array}{l}\text { Parameter estimate } \\
\qquad(S E) \chi^{2}(1)\end{array}$ & $\begin{array}{l}\text { Test of age group } \\
\text { difference } \chi^{2}(1)\end{array}$ \\
\hline \multirow[t]{7}{*}{ Pretest performance } & 1 & $\begin{array}{c}-.546 \\
13.70\end{array}$ & $\begin{array}{c}-.225(.153) \\
182\end{array}$ & \multirow{2}{*}{2.74} \\
\hline & \multirow[t]{2}{*}{2} & $-.398(.108)$ & $-.514(.121)$ & \\
\hline & & 11.53 & 12.91 & \multirow[t]{2}{*}{0.51} \\
\hline & \multirow[t]{2}{*}{4} & $-.408(.113)$ & $-.171(.176)$ & \\
\hline & & 11.18 & .81 & \multirow[t]{2}{*}{1.39} \\
\hline & \multirow[t]{2}{*}{8} & $-.296(.095)$ & $.096(.204)$ & \\
\hline & & 8.51 & .24 & \multirow{2}{*}{$\begin{array}{l}3.71 \\
0.19\end{array}$} \\
\hline \multirow[t]{8}{*}{ Average use of effective strategies } & \multirow[t]{2}{*}{1} & $.475(.316)$ & $.310(.218)$ & \\
\hline & & 2.24 & 1.95 & \\
\hline & \multirow[t]{2}{*}{2} & $.784(.288)$ & $.127(.192)$ & \multirow{3}{*}{3.57} \\
\hline & & 7.12 & .43 & \\
\hline & \multirow[t]{2}{*}{4} & $\mathbf{. 9 2 4}(.319)$ & $.304(.189)$ & \\
\hline & & 8.06 & 2.44 & \multirow[t]{2}{*}{2.80} \\
\hline & \multirow[t]{2}{*}{8} & $\mathbf{. 6 4 3}(.296)$ & $.364(.203)$ & \\
\hline & & 4.62 & 2.87 & 0.62 \\
\hline \multirow[t]{9}{*}{ Performance improvement across sessions } & & & & \multirow{3}{*}{9.79} \\
\hline & \multirow[t]{2}{*}{1} & $\mathbf{4 . 9 8 5}(.804)$ & $.547(1.175)$ & \\
\hline & & 31.32 & .21 & \\
\hline & \multirow[t]{2}{*}{2} & $\mathbf{5 . 7 7 0}(.696)$ & $1.899(.974)$ & \multirow{3}{*}{10.65} \\
\hline & & 53.55 & 3.52 & \\
\hline & \multirow[t]{2}{*}{4} & $6.651(.793)$ & $.673(1.078)$ & \\
\hline & & 52.68 & .37 & \multirow[t]{2}{*}{20.58} \\
\hline & \multirow[t]{2}{*}{8} & $6.298(.774)$ & $-.193(1.171)$ & \\
\hline & & 49.66 & .03 & 22.97 \\
\hline \multirow[t]{8}{*}{ Coupling of strategy use and performance across task blocks } & \multirow[t]{2}{*}{1} & $.399(.156)$ & $.075(.243)$ & \multirow{3}{*}{1.27} \\
\hline & & 6.10 & .10 & \\
\hline & \multirow[t]{2}{*}{2} & $.164(.151)$ & .634 (.199) & \\
\hline & & 1.15 & 8.25 & \multirow[t]{2}{*}{3.37} \\
\hline & \multirow[t]{2}{*}{4} & $.173(.168)$ & $.474(.216)$ & \\
\hline & & 1.04 & 4.05 & \multirow[t]{2}{*}{1.17} \\
\hline & 8 & $.175(.151)$ & $.490(.215)$ & \\
\hline & & 1.32 & 4.23 & 1.39 \\
\hline
\end{tabular}

Note. Boldface indicates significant parameter estimates according to the chi-square test.

use of effective (but effortful) associative mnemonics (e.g., Dunlosky \& Hertzog, 2001; Naveh-Benjamin, Brav, \& Levy, 2007; Tournier \& Postal, 2011). On average, older adults were more likely to use the less demanding and less effective rote repetition strategy despite the possibility that making self-reports about the different strategies might have encouraged them to consider and implement more effective strategies. These tendencies were maintained across practice and appear to be one reason why older adults' PA recall did not improve as much as younger adults' recall despite extended practice.

\section{Intraindividual Strategy Variability}

What is novel about the present findings is that both younger and older adults manifested reliable IAV in reported effective strategy use across lists during practice, despite older adults' lower average levels of use. There were robust age differences in this variability, with older adults manifesting less IAV. As with the other cognitive variables in this study, older adults show less, not more IAV in PA recall across different lists (Schmiedek et al., 2013; see also Allaire \& Marsiske, 2005). The present study shows the same pattern of lower IAV in effective strategy use for older adults.

Why would we observe IAV in the use of effective mnemonic strategies across days of practice? This is an open question. Strategic variability can reflect adaptive strategy switching, in which people use different strategies for different items, possibly because some items afford it. Metacognitive theory argues strongly that adaptive strategy switching enhances cognitive performance (e.g., Bjork et al., 2013; Winne, 1996). For example, an item like "57-Cows" might be efficiently encoded on the basis of Heinz (57 Varieties) ketchup as an image of a hamburger dressed with ketchup; this affordance would be in our lists happenstance given random selection of number and noun, and would have to be quickly recognized and leveraged to generate the mediator. For other items, possible sentence mediators might come to mind. We did encounter instances of people reporting using multiple normatively effective strategies for a given list, and the fact that this effect was observed throughout practice suggests it could have been, to a degree, adaptive strategy switching rather than just initial strategy exploration. By this account lower IAV in older 
adults could reflect less adaptive adjustment of strategy use during practice lists.

However, other contextual factors and within-person characteristics might explain the IAV in effective strategy use, including day to day fluctuation in affect, motivation, health, and cognitive control (e.g., Brose, Schmiedek, Lövdén, \& Lindenberger, 2011; Lemaire, 2010; Ram et al., 2005). Individuals could vary from day to day in the degree to which they are motivated to or are capable of engaging in effortful strategic processing. If so, these fluctuating influences were apparently more likely to be operating in younger adults than older adults (Schmiedek et al., 2013).

\section{Coupling of IAV in Strategy Use and PA Recall}

Not only did our older adults show lower levels of IAV in strategic behavior during practice sessions, they also manifested a lesser degree of coupling of that variability with PA recall performance. In other words, the difference in PA performance between lists where effective strategies were used, relative to when they were not, was greater for younger adults.

Younger adults also appear to have been optimizing strategy effectiveness with increasing practice; on average, they showed stronger coupling of variability in strategy use with recall performance late in practice, whereas older adults did not. We do not have definitive evidence about the reasons for these patterns of strategy-performance coupling. One possible interpretation is based on the strategic discovery idea (Siegler, 1999, 2007). If strategy variability in this task reflects in part a process of strategic discovery, in which individuals learn whether different strategies are effective, then older adults are less likely to engage in strategic discovery during practice (lower within-person variability in strategy use) and are also less likely to discover how to optimize effective strategy implementation despite extended practice. The older adults' average tendency to rely more on the ineffective strategy of rote repetition may have contributed to this effect. By this account, older adults manifest a kind of utilization deficiency despite extended practice (see Dunlosky et al., 2005).

We also detected reliable random effects in the interaction of Block and coupling within the older group, even though the average effect (as manifested in the fixed effect of the interaction of Block with coupling) was not reliable. These individual differences suggest that even though, on average, older adults were less likely to hone effective strategy use with practice, at least some older adults did so, resulting in stronger coupling effects of effective strategy use with recall performance. Future research should focus on explaining this heterogeneity in coupling effects in the older adult population.

One important feature of the present study is that it used pretest recall performance to adjust presentation times experienced during practice by participants. This design feature was used to ensure that extended practice would not produce ceiling effects in practice performance, while also keeping practice performance benefits more similar across persons differing in underlying episodic memory ability. It is possible that this design feature may be one reason for the individual differences in coupling effects seen in the older adults. It may have promoted strategy IAV in some participants and inhibited it in others. Limited encoding time presents particular difficulty for implementing some effective associative strategies such as interactive imagery (e.g., Robinson, Hertzog, \& Dun- losky, 2006). This is especially true with abstract item elements like numbers, which probably impose an additional time cost of translating an arbitrary number into a meaningful token to associate with target words. For individuals persistent in using strategies despite rapid presentation rates, the efficiency of encoding processes is likely to improve over time with sustained practice at the given presentation time despite any punishment experienced when more demanding strategies cannot be produced in the available time. These individuals would be more likely to experience what can be accomplished and what benefits (if any) they glean from implementing, refining, and honing particular strategic approaches. On the other hand, limited encoding time might inhibit strategic exploration in those who lack confidence in their ability to implement such strategies and experience initial difficulty when attempting to do so, which may be more typical with older adults (e.g., Hastings \& West, 2011).

\section{Practice Variables That Predict Posttest Recall Improvements}

Mean strategy use. Most studies of memory training generically assume improvements in strategic encoding behavior without attempting to measure it. The present results show that selfreported strategic behavior during practice, on average, forecasts individual differences in posttest recall improvements. Within the sample of younger adults, gains from pretest to posttest-reflecting long-term benefits of practice-were predicted by average use of effective strategies and by the degree of improvement of recall performance during the practice sessions. However, these effects were either not significant or reliably lower in magnitude within the older group. The pattern of results suggests that one reason why extended practice magnifies (rather than attenuates) age group differences in associative recall is that strategy use is better optimized in younger adults than in older adults by practice-related experience. It magnifies individual differences within age groups as well, presumably because practice serves to uncover and reinforce individual differences in memory-related skills, including encoding strategies (Lövdén, Bäckman, Lindenberger, Schaefer, \& Schmiedek, 2010; cf. Kliegl et al., 1989). Our results argue for age-related reductions in the plasticity of recall performance in extended practice paradigms (see Lindenberger, 2014), and implicate reduced effectiveness of strategic encoding as a key manifestation of age-related constraints on plasticity.

Coupling of strategy use and recall during practice affects posttest performance gains. Perhaps the most important new finding from this study is that strategy IAV has functional consequences for recall, not just within practice but also extending to predict pretest-posttest gains. Our within-person analyses detected reliable random effects (between-person differences) in the strategy-recall coupling effects during practice for both age groups, and these individual differences also predicted posttest recall gains within the older sample. These effects occur in addition to the effect of mean level of effective strategy use, showing that both average level of effective strategy use and the consequences of IAV in effective strategy use influence performance gains at posttest. In short, use of high-quality associative mnemonics benefit associative recall, both in the aggregate, in terms of explaining IAV in practice recall, and in predicting posttest per- 
formance gains. However, the latter effect was seen only for older adults, not younger adults.

Generalizing from Siegler's $(1997,2006,2007)$ work, we had expected that (essentially any and all) individuals who showed stronger coupling of effective strategy use and recall during practice would also demonstrate greater performance gains from pretest to posttest. If younger adults' variability was a stronger indicator of adaptive self-regulation during practice, as well as better implementation of effective strategies when they were well-suited to an item, one would expect this type of adaptivity to produce greater benefits on the posttest. Younger adults manifested stronger within-person coupling, on average, and greater performance improvements. However, these individual differences in coupling effects during practice for younger adults did not reliably predict individual differences in posttest performance gains except for the fastest $1 \mathrm{~s}$ presentation time).

How can we make sense of this pattern of results? We speculate that the extensive practice provided in COGITO was sufficient to encourage the vast majority of younger adults to gain knowledge and experience about which strategies were effective for them (despite individual differences in strategy-related performance gains during practice), making it possible for them to optimize implementation of these strategies during practice and at posttest. In contrast, older adults showed weaker strategy IAV, as noted earlier, with many older adults likely to rely solely on the less effective repetition strategy. Older adults also showed lower levels of coupling of IAV in strategy and recall during practice. Yet, within the older group, individuals who performed higher at pretest manifested stronger coupling between strategic behavior and recall during practice lists, and those manifesting stronger coupling during practice also experienced larger posttest improvements in memory performance. This pattern encourages the inference that strategic variability in older adults is not necessarily the norm, but that it is highly adaptive when it occurs.

The reasons for this outcome are unclear, and multiple explanations are possible. It could indicate multiple sources of strategic variability, some of which are maladaptive for certain persons (above and beyond the normative positive coupling effect). It could reflect limited benefit in those persons predominantly using rote repetition but occasionally mixing in an effective strategy (but only for a few items), with this limitation carrying over into the posttest. Hinault, Lemaire, and Touron (2016) argued that older adults are less adaptive at switching strategies under experimenter instructions to do so. Therefore, another possible interpretation of our coupling effects is that some older adults in unsupervised practice contexts also pay costs for strategic flexibility and hence are relatively less likely to be adaptive in using effective strategies at posttest (see also Hertzog et al., 2012).

Finally, we need to keep in mind that the range of individual differences is large, especially in old age. It is likely that older adults differ in the extent to which they behave strategically during practice in a manner that is consistent with younger adults' behavior; in particular, some of them may experience coupling between variations in strategy use and recall more often than others. Older adults who are more likely to experience such coupling during practice may also be more likely to learn about strategy effects and benefit at posttest from using them, in line with the general proposition that superior performance in old age is often marked by the maintenance of youth-like processing (Nyberg, Lövdén,
Riklund, Lindenberger, \& Bäckman, 2012). Follow-up analyses that capture the qualitative nature of IAV in strategy effectiveness within the group of older adults may shed light on why some older adults show stronger coupling effects.

\section{Study Limitations}

We acknowledge several limitations of this study. First, as already mentioned, we did not measure strategic behavior during the posttest itself. The intensive multivariate COGITO study design precluded allocating the additional time needed to collect strategy reports in the associative recall test at posttest. Second, the degree of strategic variability observed in a given study on memory test practice may depend upon its particular experimental arrangements. For instance, self-paced study time might lead to adoption of effective strategies by more participants, and might provide better opportunity to test time-demanding strategies and discover their recall benefits. Third, our strategy reports during practice assessed strategy use only at the aggregate list level. Item-level strategy reports have proved useful in scaling the connection between degree of effective strategy use and performance (e.g., Bailey et al., 2009). Fourth, we did not obtain mediator reports (i.e., descriptions of the mediators that were generated-e.g., Hertzog et al., 2013) that could have been used to determine whether the nature and quality of strategy implementation improved with practice and accounted for the greater coupling of effective strategy use and recall in the younger adults. Finally, we assessed mediational strategies for associating relatively difficult number-noun PA items. An anonymous reviewer argued that the task has limited ecological validity. It is an open question as to whether strategy discovery and optimization processes would differ when practicing other types of episodic memory tasks.

\section{Outlook}

Despite the age differences observed here, we return to the observation that (at least some) older adults did benefit from practicing strategies over the 100 days of this study. Flexible allocation of encoding strategies, rehearsal, and testing can have major benefits for long-term retention of new information (e.g., Pyc \& Rawson, 2010). A critical question for the future is whether structuring and facilitating such flexibility through targeted training would generate even greater performance improvements than seen here, especially in older adults who appear resistant to experimenting with different mnemonic strategies. Another question of interest is the range of explanations for inertial resistance to adaptive strategy variability within the older group. Are those older adults who are less variable in strategy use more influenced by, say, limitations in relevant cognitive resources needed to implement strategies? Alternatively, are they functionally capable to implement the strategies but constrained by other variables, such as a deficient task mental model or cognitive style (e.g., Touron, 2015)? If the constraints involve stylistic preferences or approaches, then it may be possible to intervene to change older individual's strategic exploration and discovery in a manner that would optimize practice and training benefits beyond the effects observed in the present study. The extant training literature has focused narrowly on training one or a few mnemonic strategies, 
but has not typically given explicit training in strategic adaptivity (e.g., flexible use of strategies depending on factors like item affordances for normative strategy success). The present results are consistent with the intriguing possibility that older adults have more room to improve their strategic encoding behavior for learning new associations. Explicit training for strategic adaptivity may produce greater training gains than seen in standard mnemonics training and increase the breadth of transfer to strategic behavior in new memory tasks, a holy grail of training research that is rarely realized in practice (but see Bailey et al., 2014; Bottiroli et al., 2013).

\section{References}

Allaire, J. C., \& Marsiske, M. (2005). Intraindividual variability may not always indicate vulnerability in elders' cognitive performance. Psychology and Aging, 20, 390-401. http://dx.doi.org/10.1037/0882-7974.20.3 390

Ardiale, E., \& Lemaire, P. (2012). Within-item strategy switching: An age comparative study in adults. Psychology and Aging, 27, 1138-1151. http://dx.doi.org/10.1037/a0027772

Baayen, R. H., Piepenbrock, R., \& Gulikers, L. (1995). The CELEX lexical database (CD-ROM). Philadelphia, PA: Linguistic Data Consortium, University of Pennsylvania.

Bailey, H., Dunlosky, J., \& Hertzog, C. (2009). Does differential strategy use account for age-related deficits in working-memory performance? Psychology and Aging, 24, 82-92. http://dx.doi.org/10.1037/a0014078

Bailey, H. R., Dunlosky, J., \& Hertzog, C. (2014). Does strategy training reduce age-related deficits in working memory? Gerontology, 60, 346356. http://dx.doi.org/10.1159/000356699

Baltes, P. B., Sowarka, D., \& Kliegl, R. (1989). Cognitive training research on fluid intelligence in old age: What can older adults achieve by themselves? Psychology and Aging, 4, 217-221. http://dx.doi.org/10 .1037/0882-7974.4.2.217

Bielak, A. A. M., Hultsch, D. F., Strauss, E., Macdonald, S. W. S., \& Hunter, M. A. (2010). Intraindividual variability in reaction time predicts cognitive outcomes 5 years later. Neuropsychology, 24, 731-741. http://dx.doi.org/10.1037/a0019802

Bieman-Copland, S., \& Charness, N. (1994). Memory knowledge and memory monitoring in adulthood. Psychology and Aging, 9, 287-302. http://dx.doi.org/10.1037/0882-7974.9.2.287

Bjork, R. A., Dunlosky, J., \& Kornell, N. (2013). Self-regulated learning: Beliefs, techniques, and illusions. Annual Review of Psychology, 64, 417-444. http://dx.doi.org/10.1146/annurev-psych-113011-143823

Bottiroli, S., Cavallini, E., Dunlosky, J., Vecchi, T., \& Hertzog, C. (2013). The importance of training memory principles: A learner-oriented approach for improving older adults' memory and transfer. Journal of Experimental Psychology: Applied, 19, 205-218. http://dx.doi.org/10 $.1037 / \mathrm{a} 0034078$

Brehmer, Y., Shing, Y. L., Heekeren, H. R., Lindenberger, U., \& Bäckman, L. (2016). Training-induced changes in subsequent-memory effects: No major differences among children, younger adults, and older adults. NeuroImage, 131, 214-225. http://dx.doi.org/10.1016/j.neuroimage 2015.11.074

Brigham, M. C., \& Pressley, M. (1988). Cognitive monitoring and strategy choice in younger and older adults. Psychology and Aging, 3, 249-257. http://dx.doi.org/10.1037/0882-7974.3.3.249

Brose, A., Schmiedek, F., Lövdén, M., \& Lindenberger, U. (2011). Normal aging dampens the link between intrusive thoughts and negative affect in reaction to daily stressors. Psychology and Aging, 26, 488-502. http:// dx.doi.org/10.1037/a0022287

Cohen, J. (1988). Statistical power analysis for the behavioural sciences (2nd ed.). Mahwah, NJ: Erlbaum.
Crutcher, R. J., \& Ericsson, K. A. (2000). The role of mediators in memory retrieval as a function of practice: Controlled mediation to direct access. Journal of Experimental Psychology: Learning, Memory, and Cognition, 26, 1297-1317. http://dx.doi.org/10.1037/0278-7393.26.5.1297

Dunlosky, J., \& Hertzog, C. (1998). Aging and deficits in associative memory: What is the role of strategy production? Psychology and Aging, 13, 597-607. http://dx.doi.org/10.1037/0882-7974.13.4.597

Dunlosky, J., \& Hertzog, C. (2001). Measuring strategy production during associative learning: The relative utility of concurrent versus retrospective reports. Memory \& Cognition, 29, 247-253. http://dx.doi.org/10 .3758/BF03194918

Dunlosky, J., Hertzog, C., \& Powell-Moman, A. (2005). The contribution of mediator-based deficiencies to age differences in associative learning. Developmental Psychology, 41, 389-400. http://dx.doi.org/10.1037/ 0012-1649.41.2.389

Grandy, T. H., Lindenberger, U., \& Schmiedek, F. (2016). Vampires and nurses are rated differently by younger and older adults-Agecomparative norms of imageability and emotionality for about 2500 German nouns. Unpublished manuscript, Center for Lifespan Psychology, Max Planck Institute for Human Development, Berlin, Germany.

Gross, A. L., \& Rebok, G. W. (2011). Memory training and strategy use in older adults: Results from the ACTIVE study. Psychology and Aging, 26, 503-517. http://dx.doi.org/10.1037/a0022687

Hastings, E. C., \& West, R. L. (2011). Goal orientation and self-efficacy in relation to memory in adulthood. Neuropsychology, Development, and Cognition: Aging, Neuropsychology and Cognition, 18B, 471-493. http://dx.doi.org/10.1080/13825585.2011.575926

Hertzog, C. (2016). Development of control processes in adulthood. In J. Dunlosky \& S. K. Tauber (Eds.), Oxford handbook of metamemory (pp. 537-558). Oxford, England: Oxford University Press.

Hertzog, C., Dixon, R. A., \& Hultsch, D. F. (1992). Intraindividual change in text recall of the elderly. Brain and Language, 42, 248-269. http:// dx.doi.org/10.1016/0093-934X(92)90100-S

Hertzog, C., Fulton, E. K., Mandviwala, L., \& Dunlosky, J. (2013). Older adults show deficits in retrieving and decoding associative mediators generated at study. Developmental Psychology, 49, 1127-1131. http:// dx.doi.org/10.1037/a0029414

Hertzog, C., McGuire, C. L., \& Lineweaver, T. T. (1998). Aging, attributions, perceived control, and strategy use in a free recall task. Neuropsychology, Development, and Cognition: Aging, Neuropsychology and Cognition, 5B, 85-106. http://dx.doi.org/10.1076/anec.5.2.85.601

Hertzog, C., Price, J., \& Dunlosky, J. (2012). Age differences in the effects of experimenter-instructed versus self-generated strategy use. Experimental Aging Research, 38, 42-62. http://dx.doi.org/10.1080/0361073X .2012 .637005

Hertzog, C., \& Shing, Y. L. (2011). Memory development across the lifespan. In K. Fingerman, C. A. Berg, T. Antonucci, \& J. Smith (Eds.), Handbook of lifespan developmental psychology (pp. 299-330). New York, NY: Springer.

Hinault, T., Dufau, S., \& Lemaire, P. (2015). Strategy combination in human cognition: A behavioral and ERP study in arithmetic. Psychonomic Bulletin \& Review, 22, 190-199. http://dx.doi.org/10.3758/ s13423-014-0656-8

Hinault, T., Lemaire, P., \& Touron, D. (2016). Aging effects is sequential modulations of poorer-strategy effects during execution of memory strategies. Memory, 25, 176-186. http://dx.doi.org/10.1080/09658211 .2016 .1146300

Hultsch, D. F., Strauss, E., Hunter, M. A., \& MacDonald, S. W. S. (2007). Intraindividual variability, cognition, and aging. In F. I. M. Craik \& T. A. Salthouse (Eds.), Handbook of cognitive aging (3rd ed., pp. 491-556). New York, NY: Psychology Press.

Jennings, J. M., Webster, L. M., Kleykamp, B. A., \& Dagenbach, D. (2005). Recollection training and transfer effects in older adults: Successful use of a repetition-lag procedure. Neuropsychology, Develop- 
ment, and Cognition: Aging, Neuropsychology and Cognition, 12B, 278-298. http://dx.doi.org/10.1080/138255890968312

Kausler, D. H. (1994). Learning and memory in normal aging. San Diego, CA: Academic Press.

Kliegl, R., Smith, J., \& Baltes, P. B. (1989). Testing-the-limits and the study of adult age differences in cognitive plasticity of a mnemonic skill. Developmental Psychology, 25, 247-256. http://dx.doi.org/10.1037/ 0012-1649.25.2.247

Lemaire, P. (2010). Cognitive strategy variations during aging. Current Directions in Psychological Science, 19, 363-369. http://dx.doi.org/10 .1177/0963721410390354

Lemaire, P., \& Leclère, M. (2014). Strategy repetition in young and older adults: A study in arithmetic. Developmental Psychology, 50, 460-468. http://dx.doi.org/10.1037/a0033527

Lindenberger, U. (2014, October 13). Human cognitive aging: Corriger la fortune? Science, 346, 572-578. http://dx.doi.org/10.1126/science .1254403

Lövdén, M., Bäckman, L., Lindenberger, U., Schaefer, S., \& Schmiedek, F. (2010). A theoretical framework for the study of adult cognitive plasticity. Psychological Bulletin, 136, 659-676. http://dx.doi.org/10.1037/ a0020080

Luo, L., \& Craik, F. I. M. (2009). Age differences in recollection: Specificity effects at retrieval. Journal of Memory and Language, 60, 421436. http://dx.doi.org/10.1016/j.jml.2009.01.005

Luwel, K., Foustana, A., Onghena, P., \& Verschaffel, L. (2013). The role of verbal and performance intelligence in children's strategy selection and execution. Learning and Individual Differences, 24, 134-138. http:// dx.doi.org/10.1016/j.lindif.2013.01.010

MacDonald, S. W. S., Hultsch, D. F., \& Dixon, R. A. (2008). Predicting impending death: Inconsistency in speed is a selective and early marker. Psychology and Aging, 23, 595-607. http://dx.doi.org/10.1037/08827974.23.3.595

McArdle, J. J. (2009). Latent variable modeling of differences and changes with longitudinal data. Annual Review of Psychology, 60, 577-605. http://dx.doi.org/10.1146/annurev.psych.60.110707.163612

Molenaar, P. C. M. (2004). A manifesto on psychology as idiographic science: Bringing the person back into scientific psychology, this time forever. Measurement: Interdisciplinary Research and Perspectives, 2, 201-218. http://dx.doi.org/10.1207/s15366359mea0204_1

Muthén, L. K., \& Muthén, B. O. (2012). Mplus user's guide. Los Angeles, CA: Author.

Naveh-Benjamin, M., Brav, T. K., \& Levy, O. (2007). The associative memory deficit of older adults: The role of strategy utilization. Psychology and Aging, 22, 202-208. http://dx.doi.org/10.1037/0882-7974.22.1 .202

Neely, A. S., \& Bäckman, L. (1995). Effects of multifactorial memory training in old age: Generalizability across tasks and individuals. The Journals of Gerontology: Psychological Sciences and Social Sciences, 50B, 134-140. http://dx.doi.org/10.1093/geronb/50B.3.P134

Nyberg, L., Lövdén, M., Riklund, K., Lindenberger, U., \& Bäckman, L. (2012). Memory aging and brain maintenance. Trends in Cognitive Sciences, 16, 292-305. http://dx.doi.org/10.1016/j.tics.2012.04.005

Old, S. R., \& Naveh-Benjamin, M. (2008). Differential effects of age on item and associative measures of memory: A meta-analysis. Psychology and Aging, 23, 104-118. http://dx.doi.org/10.1037/0882-7974.23.1.104

Ornstein, P. A., \& Light, L. L. (2010). Memory development across the life span. In W. F. Overton (Vol. Ed.) \& R. M. Lerner (Series Ed.), The handbook of life-span development: Cognition, biology, and methods (Vol. 1, pp 259-305). Hoboken, NJ: John Wiley \& Sons, Inc.

Paivio, A. (2007). Mind and its evolution: A dual coding theoretical approach. Mahwah, NJ: Erlbaum Publishers.

Price, J., Hertzog, C., \& Dunlosky, J. (2008). Age-related differences in strategy knowledge updating: Blocked testing produces greater improvements in metacognitive accuracy for younger than older adults. Neuro- psychology, Development, and Cognition: Aging, Neuropsychology and Cognition, 15B, 601-626. http://dx.doi.org/10.1080/1382558080 1956225

Pyc, M. A., \& Rawson, K. A. (2010, October 13). Why testing improves memory: Mediator effectiveness hypothesis. Science, 330, 335. http:// dx.doi.org/10.1126/science.1191465

Ram, N., Rabbitt, P., Stollery, B., \& Nesselroade, J. R. (2005). Cognitive performance inconsistency: Intraindividual change and variability. Psychology and Aging, 20, 623-633. http://dx.doi.org/10.1037/0882-7974 .20.4.623

Richardson, J. T. E. (1998). The availability and effectiveness of reported mediators in associative learning: A historical review and an experimental investigation. Psychonomic Bulletin \& Review, 5, 597-614. http:// dx.doi.org/10.3758/BF03208837

Robinson, A., Hertzog, C., \& Dunlosky, J. (2006). Aging, encoding fluency, and metacognitive monitoring. Neuropsychology, Development, and Cognition: Aging, Neuropsychology and Cognition, 13B, 458-478. http://dx.doi.org/10.1080/13825580600572983

Saczynski, J. S., Rebok, G. W., Whitfield, K. E., \& Plude, D. L. (2007) Spontaneous production and use of mnemonic strategies in older adults. Experimental Aging Research, 33, 273-294. http://dx.doi.org/10.1080/ 03610730701318899

Salthouse, T. A., Nesselroade, J. R., \& Berish, D. E. (2006). Short-term variability in cognitive performance and the calibration of longitudinal change. Journal of Gerontology: Psychological Sciences and Social Sciences, 61B, 144-151. http://dx.doi.org/10.1093/geronb/61.3.P144

SAS Institute Inc. (2008). SAS/STAT 9.2 user's guide. Cary, NC: Author. Schmiedek, F., Bauer, C., Lövdén, M., Brose, A., \& Lindenberger, U. (2010). Cognitive enrichment in old age: Web-based training programs. The Journal of Gerontopsychology and Geriatric Psychiatry, 23, 59-67. http://dx.doi.org/10.1024/1662-9647/a000013

Schmiedek, F., Lövdén, M., \& Lindenberger, U. (2010). Hundred days of cognitive training enhance broad cognitive abilities in adulthood: Findings from the COGITO study. Frontiers in Aging Neuroscience, 2, 1-10.

Schmiedek, F., Lövdén, M., \& Lindenberger, U. (2013). Keeping it steady: Older adults perform more consistently on cognitive tasks than younger adults. Psychological Science, 24, 1747-1754. http://dx.doi.org/10 $.1177 / 0956797613479611$

Shing, Y. L., Brehmer, Y., Heekeren, H. R., Bäckman, L., \& Lindenberger, U. (2016). Neural activation patterns of successful episodic encoding: Reorganization during childhood, maintenance in old age. Developmental Cognitive Neuroscience, 20, 59-69. http://dx.doi.org/10.1016/j.den 2016.06.003

Shing, Y. L., Werkle-Bergner, M., Brehmer, Y., Müller, V., Li, S. C., \& Lindenberger, U. (2010). Episodic memory across the lifespan: The contributions of associative and strategic components. Neuroscience and Biobehavioral Reviews, 34, 1080-1091. http://dx.doi.org/10.1016/j neubiorev.2009.11.002

Shing, Y. L., Werkle-Bergner, M., Li, S.-C., \& Lindenberger, U. (2008). Associative and strategic components of episodic memory: A life-span dissociation. Journal of Experimental Psychology: General, 137, 495513. http://dx.doi.org/10.1037/0096-3445.137.3.495

Siegler, R. S. (1999). Strategic development. Trends in Cognitive Sciences, 3, 430-435. http://dx.doi.org/10.1016/S1364-6613(99)01372-8

Siegler, R. S. (2006). Microgenetic analyses of learning. In D. S. Kuhn, R. S. Siegler, W. Damon, \& R. M. Lerner (Eds.), Handbook of child psychology: Vol. 2. Cognition, perception, and language (6th ed., pp. 464-510). Hoboken, NJ: Wiley.

Siegler, R. S. (2007). Cognitive variability. Developmental Science, 10, 104-109. http://dx.doi.org/10.1111/j.1467-7687.2007.00571.x

Siegler, R. S., \& Chen, Z. (2008). Differentiation and integration: Guiding principles for analyzing cognitive change. Developmental Science, 11, 433-448. http://dx.doi.org/10.1111/j.1467-7687.2008.00689.x 
Siegler, R. S., \& Lemaire, P. (1997). Older and younger adults' strategy choices in multiplication: Testing predictions of ASCM using the choice/no-choice method. Journal of Experimental Psychology: General, 126, 71-92. http://dx.doi.org/10.1037/0096-3445.126.1.71

Sliwinski, M. J., Smyth, J. M., Hofer, S. M., \& Stawski, R. S. (2006). Intraindividual coupling of daily stress and cognition. Psychology and Aging, 21, 545-557. http://dx.doi.org/10.1037/0882-7974.21.3.545

Stine-Morrow, E. A. L., Miller, L. M. S., \& Hertzog, C. (2006). Aging and self-regulated language processing. Psychological Bulletin, 132, 582606. http://dx.doi.org/10.1037/0033-2909.132.4.582

Tournier, I., \& Postal, V. (2011). Strategy selection and aging: Impact of item concreteness in paired-associate task. Neuropsychology, Development, and Cognition: Aging, Neuropsychology and Cognition, 18B, 195-213. http://dx.doi.org/10.1080/13825585.2010.525623

Touron, D. R. (2015). Memory avoidance by older adults: When 'old dogs' won't perform their new tricks. Current Directions in Psychological Science, 24, 170-176. http://dx.doi.org/10.1177/0963721414563730

Verhaeghen, P., \& Marcoen, A. (1994). Production deficiency hypothesis revisited: Adult age differences in strategy use as a function of processing resources. Neuropsychology, Development, and Cognition: Aging, Neuropsychology and Cognition, 1B, 323-338. http://dx.doi.org/10 $.1080 / 13825589408256585$
Voelkle, M. C., Brose, A., Schmiedek, F., \& Lindenberger, U. (2014) Toward a unified framework for the study of between-person and within-person structures: Building a bridge between two research paradigms. Multivariate Behavioral Research, 49, 193-213. http://dx.doi .org/10.1080/00273171.2014.889593

West, R. L., Bagwell, D. K., \& Dark-Freudeman, A. (2008). Self-efficacy and memory aging: The impact of a memory intervention based on self-efficacy. Neuropsychology, Development, and Cognition: Aging, Neuropsychology and Cognition, 15B, 302-329. http://dx.doi.org/10 $.1080 / 13825580701440510$

Winne, P. H. (1996). A metacognitive view of individual differences in self-regulated learning. Learning and Individual Differences, 8, 327353. http://dx.doi.org/10.1016/S1041-6080(96)90022-9

Wolff, J. K., Brose, A., Lövdén, M., Tesch-Römer, C., Lindenberger, U., \& Schmiedek, F. (2012). Health is health is health? Age differences in intraindividual variability and in within-person versus between-person factor structures of self-reported health complaints. Psychology and Aging, 27, 881-891. http://dx.doi.org/10.1037/a0029125

Received August 11, 2016 Revision received April 17, 2017 Accepted April 24, 2017

\section{E-Mail Notification of Your Latest Issue Online!}

Would you like to know when the next issue of your favorite APA journal will be available online? This service is now available to you. Sign up at https://my.apa.org/portal/alerts/ and you will be notified by e-mail when issues of interest to you become available! 